\title{
ICT Providers: A Relevant Topic for Business and Information Systems Engineering?
}

DOI 10.1007/s12599-012-0235-3

\section{The Authors}

Prof. Dr. Thomas Hess

Institut für Wirtschaftsinformatik

und Neue Medien

LMU München

Ludwigstrasse 28

80539 München

Germany

thess@bwl.Imu.de

Prof. Dr. Peter Loos ( $\varangle)$

IWi at DFKI

Saarland University

66123 Saarbrücken

Germany

loos@iwi.uni-sb.de

Prof. Dr. Peter Buxmann

Dr. Koray Erek

Prof. Dr. Ulrich Frank

Jürgen Gallmann

Prof. Dr. Martin Gersch

Prof. Dr. Rüdiger Zarnekow

Prof. Dr. Peter Zencke

Published online: 2012-11-08

This article is also available in German in print and via http://www. wirtschaftsinformatik.de: Hess T, Loos P (2012) IKT-Anbieter als Thema der Wirtschaftsinformatik? WIRTSCHAFTSINFORMATIK. doi: 10.1007/ s11576-012-0339-x.

(C) Springer Fachmedien Wiesbaden 2012

\section{Introduction}

Business and information systems engineering traditionally deals with the use of information and communication technologies in companies. The main focus is on the content-related design of business application systems in companies as well as on the ICS/ICT management in companies. The established range of topics includes ERP and SCM systems, business concepts built thereon and adequate development procedures as well as questions regarding the alignment between ICT and a company, IT architecture management or comprehensive questions of the ICT strategy. On the basis of this orientation business and information systems engineering has been widely established as an academic subject, particularly in German-speaking countries.

A slow but steady reduction in the production intensity of IT can be observed in the applying companies. Cloud computing has intensified this trend even further. An ICT industry making a global turnover of approx. $\$ 2,700$ bn has emerged at the same time. This industry has produced a number of exciting companies ranging from IBM, Microsoft, SAP and Apple to Tata as well as innumerable small companies. So far, business and information systems engineering has dealt with these companies rather occasionally, for example when they are spin-offs of former ICT departments. This raises the question whether it should be like that in the future. The observation that the number of "trained" business and information systems engineers starting their own business or being a member of the board of directors of an ICT company is still quite small makes this question seem even more urgent. This gives rise to the question as to how appealing the university subject business and information systems engineering is to freshers.

There are some arguments which speak for opening up business and information systems engineering to ICT providers. Compared to traditional business administration, business and information systems engineering could contribute specific technological knowledge and understanding of ICT applications for users. Previous achievements as to the efficient software development or the management of data processing centers would also be useful. On the other hand, business and information systems engineering would have to open up to completely new subject areas, such as the pricing process for network services or growth strategies of software companies, and give up some well-established theoretical paths, such as putting a strong focus on the information system as a conceptual point of reference. All these aspects have to be considered with regard to the added value of this subject as a research area, its appeal as a major or minor subject and, thus, with regard to the impact on companies and government sponsors.

We asked the following experts from the field of science and daily business to give their opinion (the experts' names are listed in alphabetical order):

- Prof. Dr. Peter Buxmann, TU Darmstadt, Fachgebiet Software Business and Information Management

- Prof. Dr. Ulrich Frank, Universität Duisburg-Essen, Lehrstuhl für Wirtschaftsinformatik und Unternehmensmodellierung

- Jürgen Gallmann, Cumulus Ventures $\mathrm{GmbH}$, Feldafing bei München

- Prof. Dr. Martin Gersch, FU Berlin, Department Business Information Systems

- Prof. Dr. Rüdiger Zarnekow und Dr. Koray Erek, TU Berlin, Lehrstuhl für Informations- und Kommunikationsmanagement

- Prof. Dr. Peter Zencke, Julius-Maximilians-Universität Würzburg, Lehrstuhl für BWL und Wirtschaftsinformatik

Peter Zencke thinks that corporate IT is on its way to become an operator and integrator of purchased platforms and he deduces that it is necessary to open up business and information systems engineering to ICT providers. In particular he emphasizes the increasing importance of the service business to providers.

Jürgen Gallmann is of the opinion that today's (strong) focus of the business and information systems engineering courses on the users is one of the reasons for the moderate importance of German ICT providers in the world market. He recommends opening up the courses to the needs of ICT providers more extensively, particularly emphasizing the aspects distribution and marketing. 
Ulrich Frank identifies five subject areas on part of ICT providers that business and information systems engineering could profitably deal with. He puts emphasis on starting points for an intensive co-operation between ICT companies and business and information systems engineers doing research at universities.

This paper presents three articles dealing with selected sub-sectors. The first, written by Peter Buxmann, points out the specific economic characteristics of the software industry and from this he derives that with regard to this industry there is a particular need for research and teaching. When discussing these questions he concludes that business and information systems engineering offers an advantage as it is a discipline combining economics and computer science.

Rüdiger Zarnekow und Koray Erek analogously demand a more intense engagement of business and information systems engineering with providers of telecommunication services. The two authors argue primarily out of technologically driven changes and practical needs.

In his article, Martin Gersch goes one step further and demands an even wider opening of business and information systems engineering, not only to ICT providers but in the future also to particularly important ICT-intensive industries, such as energy supply and medical technology, and with that, beyond traditional "ICT-intensive industries", such as banks and media companies.

These six authors positively consider the question of opening business and information systems engineering. It is to be hoped that the recognizable activities of a stronger awareness for ICT providers in research and teaching are going to increase in the future.

If you want to comment on this article or on any other article published in the Business \& Information Systems Engineering journal, please email your comment (not more than two pages) to loos@iwi.uni-sb.de.

Prof. Dr. Thomas Hess Institut für Wirtschaftsinformatik und Neue Medien

LMU München

Prof. Dr. Peter Loos IWi at DFKI

Saarland University

\section{Business and Information Systems Engineering, Standard Business Software and IT Services}

F. P. Brooks, IBM development manager of the famous IBM/360 mainframe, was one of the first to predict the trend towards a mass market for software in the course of which individual companies will no longer develop their IT solutions themselves.

In the field of business applications SAP coined the term standard software. The development of IT solutions in close co-operation with customers so that they could be used in multiple ways has been SAP's first objective since 1972. In this way, the high development costs of software could be divided among many customers. Only in this way, many customers were able to afford those IT solutions in the first place. The second objective has been to develop not only individual business solutions for individual departments, such as finance or distribution, but to integrate the functions of all the important departments of a company by means of data and processes. The third objective has been to realize this integration by means of real-time processing with the data being synchronized at the time of the business transaction and without additional, complex and errorprone work. Today we call such IT solutions ERP systems, an area where SAP has become the global market leader. SAP's close connection to business and information systems engineering in this development period over 30 years has been a success factor for SAP and it has been stimulating for the German business and information systems engineering.

Right from the start, the development of modern business applications was closely intertwined to the dynamic development of the computer and communications technology. New internet technologies made it possible to develop new applications such as CRM and SCM, which extended the in-house integration with ERP by the integration of a company's external relations with ERP II, what is nowadays called business platform. The platforms of SAP and other producers such as Oracle or Microsoft, etc are used by tens of thousands of companies, without which no contemporary business transaction can be carried out. These systems are crucial to a company's success and their shaping has a decisive impact on their users' competitiveness. These business platforms are used over decades and they are also linked across companies. These platforms are growing in accordance with the users' requirements, just as F.P. Brooks predicted, and in case of an accelerated technological development they are subject to constant modernization and innovation.

Nowadays, the core task of business and information systems engineering, namely business integration, is mostly accomplished by platforms of global IT solution providers, which are adapted and complemented in accordance with a company's needs. The question as to how these IT solutions are designed and developed by the engineering departments of the large ICT providers is becoming less and less important to the companies using those platforms. However, this also implies that the companies' IT specialists' need for know-how as to developmentoriented topics of business and information systems engineering, such as data and process models, meta-modeling, IT application architecture, etc., is decreasing. Relevant to today's companies, however, is the consumability of the platforms, how efficient and open they are, how easy it is to adapt or complement them, which user interfaces they support and on which devices they support them, and what their operating costs are.

Operating platforms are still the main domain of corporate IT. However, in the course of industrializing IT this task will lose importance with outsourcers and cloud providers taking over the operation of companies' IT inexpensively and turning it into a professional business of its own.

With this development the qualification requirements of specialist departments and the companies' IT are changing fundamentally. The good news for business and information systems engineers is that information systems as an area of work will become more important for the organization of a company's business. The variety of organizing a company's business is extensive in the different industries and structures are complex. In the future, business and information systems engineers will need to have a practical understanding of how large business platforms can be used and how their application can be evaluated. Naturally, good technological know-how is required, however it has less to do with systems development and more with the application of integration tools, adaption tools and add-on tools including all web 
tools of the platforms. The core competency is the combination of business knowledge the design of differentiating business models and their mapping and implementation on existing platforms. In the future this will still be an exciting area of work challenging technical, analytical and communicative skills.

All in all the whole ICT industry is changing from a development-oriented product business to an IT services and solutions business. IBM has been most consistent in implementing those changes in recent years. With regard to the knowledge workers in this growing service business, all the above core competencies of business and information systems engineering are urgently sought after. In the IT solutions business all core competencies such as platform and application know-how, integration and adaption know-how have to be re-combined again and again in accordance with the customers' specific needs. Certainly, there will still be software developers focusing on product development. However, these do not only include the global platform providers, but also a growing number of specialist providers. In product development, the differentiation of specialized application know-how is growing to become more important than mere technical development skills as well.

Hence, the tasks of the business and information systems engineers of the future will increasingly lie in the serviceoriented IT industry. The understanding of these services and the partially complex structures together with their availability to customers is an important topic, which most of today's business and information systems engineers still know little about.

Therefore, it would be interesting if business and information systems engineering particularly dealt with the service processes of its own ICT industry. In terms of understanding one's own industry, which is used in business and information systems engineering, this would be of high practical relevance.

These service processes can also be considered as processes related to the digital product software, particularly business software. Since we are increasingly pursuing a digital transformation of the entire business world, the know-how as to service processes related to digital products will also become important in many other industries.

Prof. Dr. Peter Zencke

\section{Players or Spectators in the Champions League?}

Recently one of Angela Merkel's meetings convened at short notice, where she met influential people from the German internet and ICT community to discuss Germany's opportunities in the internet and ICT industry which is becoming more and more important all over the world. The results of this meeting have not been made public, but we have to be realistic and understand that from a global perspective Germany's role in this industry is not of major significance. Despite some striking successes we are rather a lightweight in this industry, i.e., seen from the global perspective we are spectators rather than players.

But if we do not come up with some good ideas as to how we can change this situation, then the entire economic performance of Germany will be affected negatively because the global business models will also be heavily influenced by the leading internet and ICT nations. Certainly, there are a number of reasons explaining the current situation. A good start is surely to look at the way we educate business and information systems engineers at our universities.

There is no doubt that the students studying business and information systems engineering get a sound and wellfounded education. However, we have to ask ourselves whether we should primarily prepare our business and information systems engineers for a career of a Chief Information Officer (CIO) of a company or whether we should alternatively also prepare them for a career as a representative of an internet or ICT providers. If we want Germany to be not only a good market for foreign providers but also an exporter of German internet and ICT solutions, in addition to SAP's and Software AG's products, then the education of our business and information systems engineers has to meet the needs of the internet and ICT providers even more. This means that apart from teaching technical and business skills the business and information systems engineering courses have to put a stronger focus on sales skills in particular and marketing-related skills in general.

However, German universities do not seem to attach great importance to the training and development of sales skills in particular or German professors do not seem to consider this to be an area where they can earn major credits in their careers. But that is exactly what the Americans do for example (American companies' investments in sales activities and qualification: \$ 800 bn; Zoltners 2006): they include the training and development of sales skills at an early stage of the education and in that way they have developed a national "gene" that is a prerequisite for the successful creation of a globally successful and unique internet and ICT industry. In addition, the Americans firmly believe that sales does not only play a subordinate but a central role as other successful entrepreneurs, such as Andrew Carnegie (1835-1919), already stated in the $19^{\text {th }}$ century: "You can take away my money and take away my factories, but leave me my sales staff und I'll be back where I was in two years".

This means that we have to teach our business and information systems engineering students not only details about software and hardware architectures, the functioning of programming languages, the modeling of processes or procedures for optimum resource planning but we have to apply the same kind of effort and quality when we tell them about monetization models, sales strategies and methods in the digital world, account management or alternative online marketing, etc. But the typical curriculum of a business and information systems engineering course lacks all these subjects. In this way we still produce a type of graduate in business and information systems engineering who will certainly be in demand in the future but who is not able to contribute much to establishing an efficient internet and ICT industry whose products are created in Germany and sold all over the world.

The adaption of the education of business and information systems engineers towards internet and ICT providers' requirements would also benefit entrepreneurial and start-up activities in Germany. Thus, we would not only be able to develop fantastic technologies in Germany, which others then sell successfully on the world market (such as the often mentioned MP3-player), but we would also celebrate the commercial success of our well-known engineering finesse here in Germany and we would have a new progressive industry that supports us in the competition with the world's most successful economies.

Jürgen Gallmann

Cumulus Ventures $\mathrm{GmbH}$ Feldafing bei München 


\section{ICT Companies: Subject of Research and Co-Operation Partners}

The question of making ICT providers a subject of business and information systems engineering-related discussions seems confusing at first glance. Especially those ICT providers developing business applications have always been a focus of attention of business and information systems engineering as their product considerably coincide with the central subject of research of business and information systems engineering. On closer examination it becomes obvious that business and information systems engineering could intensify research related to ICT providers. In extreme cases this would lead to business and information systems engineering being more sectororiented similar to banking management. However, such an orientation of this subject is not to be analyzed further in this article. Thus, the consideration of ICT users is an essential task of business and information systems engineering for a good reason. Furthermore, narrowing business and information systems engineering down to ICT providers would not be compatible with the objective of providing our graduates with ample and sound qualifications, which enable them to take on responsibilities in a number of sectors. Therefore, a discussion of reorientation of business and information systems engineering will be omitted. Rather we will look at five fields of research where a more intense analysis of specific problems and challenges of ICT providers could be profitable.

Design of future information systems: The development of innovative business information systems is one of the central research topics of business and information systems engineering. This includes, e.g., modeling languages, methods, reference models or systems architectures. Research at universities is facing the big challenge that the available resources are often not sufficient to implement and test complex systems. Research that is excluded from restrictions placed by current systems architectures and standards offers the opportunity to show interesting perspectives on the development of future systems generations - this may even be profitable to large ICT companies that have their own research department. In order to use the potential for research and long-term product development resulting therefrom, new forms of co-operation are required. On the one hand, they involve the differentiated and supported exchanges of mutual interests between ICT providers and universities. On the other hand, apart from an appropriate cooperation with users this also requires a closer cooperation between universities in order to pool resources. Although engineering can only partially serve as a suitable example, it still provides numerous examples of how research at universities can be successfully linked to companies' R\&D activities.

Design of new business models: In contrast to engineering, business and information systems engineering is also based on economics. On the one hand, this is reflected by the fact that it does not consider information systems to be independent regarding the design of the supported system of action. On the other hand, business and information systems engineering also analyses which products and services will result from this or be required due to information technology. Furthermore, the ICT providers' perspective gives rise to a number of interesting research questions which is going to affect the design of promising business models. This includes, e.g., business models, which are largely based on a differentiated range of services, which is going to eclipse the distribution of traditional IT products. However, the design and valuation of such services and the necessary information systems are not only important to ICT providers but also to prospective customers, because they allow them to restructure their value chain which has a positive effect on their competitiveness. In addition, it is conceivable that new business models result from a closer co-operation with other providers and users, i.e., new forms of division of labor and coordination. Various research questions are connected to that such as suitable instruments, e.g., in the form of reference models, computerbased coordination mechanisms or incentive systems.

Consideration of dedicated management tasks: ICT companies are facing a number of specific management challenges, which are important to business and information systems engineering. They include the leadership of employees who differ considerably in terms of their professional and cultural background, the management of projects which take place in an international context and the strategic planning in a highly dynamic environment that is characterized by numer- ous contingencies. At the interface to economics there are two interesting areas of research; on the one hand, the identification and analysis of specific factors influencing successful management and, on the other hand, the development of dedicated incentive systems and methods of management. Besides, the design of methods and tools for project management and the development of dedicated management information systems are further interesting areas of research.

Development of qualification profiles: Even though I feel it is not advisable to exclusively align the qualification of business and information systems engineers to the ICT providers' needs, a differentiated consideration of future requirements for the design and implementation of curricula is quite reasonable. This refers to the specific management tasks mentioned, but above all this includes dedicated technical qualifications required by the professional handling of future information systems. Of course, this does not primarily include product knowledge but concepts and methods that offer a sound basis for the solution of complex problems beyond today's widespread systems. To understand the ICT providers' qualification needs both current requirements and requirements deriving from future business models have to be taken into consideration.

Improving the public perception of business and information systems engineering: The widely known success stories of some outstanding ICT companies have contributed towards promoting the reputation of business and information systems engineers. Nevertheless, business and information systems engineering has not yet reached the status it deserves given the economic and social importance of its research subject. This circumstance is connected to a series of consequences that are unpleasant for both, business and information systems engineering and ICT companies. Thus, the number of business and information systems engineering courses offered by universities is far less than that of engineering disciplines; as mentioned above that makes the implementation of complex projects very difficult. The DFG's list of subject areas still does not include business and information systems engineering - as a consequence the relative portion of relevant funding is dwindling. Since public awareness of "business and information systems engineers" is low and since there are often vague prejudices against this profession, the demand for, highly 
talented and ambitious high-school graduates for university places in this subject is low. The lack of qualified university graduates, which is directly linked to the low demand, poses considerable problems for ICT providers. Among others it was this lack of qualified university graduates that considerably promoted together with the active support of some large ICT companies - the creation of this subject. Today it would be desirable that ICT providers cooperate with representatives of business and information systems engineering to develop and implement strategies to promote public awareness of this subject.

Prof. Dr. Ulrich Frank Universität Duisburg-Essen Lehrstuhl für Wirtschaftsinformatik und Unternehmensmodellierung

\section{The Software Industry - An Appealing Subject for Research and Teaching in the Field of Business and Information Systems Engineering}

"Software is no business like other businesses". Against the backdrop of this statement by Michael Cusumano (2004) of the Massachusetts Institute of Technology this article is going to deal with the question why a comprehensive economic analysis of the software industry from the providers' perspective - hereafter referred to simply as software business - is a highly interesting and appealing subject area for research and teaching in the field of business and information systems engineering.

\subsection{Software Business as a Research Subject}

Establishing "software business" as an independent area of research is only a viable option if the software industry has special economic characteristics that distinguish it completely from the other industries. This article is going to show that such industry-specific differences can be traced back to the features of the product software, on the one hand, and, on the other hand, to the structure of software markets.

One special characteristic of software products is that they can be reproduced at low costs - just as other digital goods. Therefore, the variable costs are virtually zero. In addition, software can be copied as often as one likes and without a loss of quality. If a copy has already been shared on the internet, copyrights and disposition rights can only be enforced at great expense. From the providers' perspective, a number of strategies and recommendations for action can be derived from this characteristic. In the end, that is why low-price strategies and the availability of free software with the aim to earn money with supplementary services are based on the cost structure of software mentioned above. Furthermore, it can be demonstrated formally that bundle strategies tend to be more advantageous the lower the variable costs of the product components.

Software markets have special characteristics, too: The unique feature that characterizes the software industry is its strong internationalization. Software can be developed globally and, within seconds, sold over the internet at very low costs. This has also resulted in a global competition between software providers. In contrast to other industries the home advantage on national markets only plays a subordinate role in many segments. German software providers make more than half of their turnover abroad - e.g., exports of the two largest German software providers, SAP AG and Software AG, account for more than $80 \%$ of sales.

A further special characteristic of software markets is that they are characterized by so-called network effects. The resulting economies of scale by the providers have a considerable impact on the software business. Due to the characteristic network effects of software, these markets are often so-called "winnertakes-it-all" markets with vendor lockins. On this basis, price and product strategies can often be derived theoretically and co-operation and takeover strategies can be explained (Buxmann et al. 2011).

These considerations demonstrate that there are some specific, economic rules for the software industry, which make it useful to establish "software business" as an independent area of research in the field of business and information systems engineering.

\subsection{Software Business in Education and Training}

"Software business" is also an appealing subject within business and information systems engineering courses (or business seminars focusing on business and information systems engineering/computer science). On the one hand, the economic theory offers numerous approaches which methodologically oriented teaching on software business could build on. These include, e.g., the theory of digital goods, the network effects theory mentioned above as well as approaches that are summarized under the term service science. On the other hand, this subject is perfectly suited including the latest developments in teaching. Business models for open source, social media and cloud providers or rather the design of platform strategies for software and app markets could be discussed on the basis of existing methodological tools.

Last but not least the establishment of a subject called software business in business and information systems engineering courses could open up new career opportunities to university graduates. A corresponding extension of the education of business and information systems engineers would be a good basis for management positions in IT or software industries. Furthermore, the skills taught could also be helpful and useful for potential entrepreneurs of software or social media businesses. Finally, new developments on software markets are highly appealing to students as recent experience has shown.

\subsection{Why Should Business and Information Systems Engineering of all Subjects Concentrate on Business Software?}

While in economics there are a number of professors and chairs that focus on fields such as finance, health care or energy, there have hardly been any professors and chairs that concentrate on the economic rules of the software industry and the strategies and business models for providers which arise from that.

As a result, business and information systems engineers might be better qualified than pure economists due to their interdisciplinary perspective for setting up the discipline "software business", since both, technological and economic knowhow, are a prerequisite for the in-depth understanding of the software industry.

In this respect, research and education in the field of business and information systems engineering could contribute to making this subject more appealing to specialists, research scientists, students and founders by considering 
the software industry from the providers' perspective.

Prof. Dr. Peter Buxmann TU Darmstadt

Fachgebiet Software Business and Information Management

\section{Importance of the ICT Providers for Business and Information Systems Engineering at the Example of the Telecommunication Industry}

Value chains in the ICT industry are becoming increasingly complex and global. Technological innovations lead to new and cross-industry competitive and cooperative structures. More and more private consumers are using complex products and services that are based on ICT. These are only three examples of current trends, which have one thing in common: Besides business and information systems engineering's traditional object of research, i.e., the company using information systems to assist its business processes and/or to gain (strategic) competitive advantages, a number of ICT providers are occurring, taking over large parts of the performance development, performance processes and the distribution of ICT services. The real net output ratio of each individual party involved is decreasing; this trend is sufficiently wellknown from other industries. Business and information systems engineering has to answer to this development and it has to integrate the special challenges and issues of ICT providers into its research and teaching content. The fact that this is still not sufficiently done is proven by the low number of workshops and tracks at central business and information systems engineering conferences that deal explicitly with ICT providers and by the low significance that is typically attributed to them in business and information systems engineering textbooks. Using the telecommunication industry as an example we are going to explain the consequences of a provider-oriented perspective and after that we are going to identify some - from our point of view - important research and teaching subjects of ICT providers.

Networks play a central role in the development and implementation of information systems; a fact caused, not least, by the increasing spread and ubiquitous use of the internet. Current trends, such as cloud computing, reinforce this development. Although business and information systems engineering has intensively dealt with issues of the networked company, internet economy, electronic business and the use of networks for a long time, yet telecommunication providers as network operators and providers of telecommunication services have still played a subordinate role. It seems that a global, working and high-performance network infrastructure is taken for granted - an opinion of ICT providers and decision takers that the authors are often faced with. Research needs are seen at best in the technical development of networks. The telecommunications industry is confronted with major challenges, which produce highly relevant (research) questions to business and information systems engineering: business models are undergoing radical changes, decreasing margins are leading to an enormous pressure to increase efficiency in the organization and its processes, and new, futureproof products and services have to be developed to secure long-term competitiveness. These new products and services are often subject to convergence phenomena and require the co-operation between ICT providers from different industries and market segments, such as telecommunication, internet, hardware, software and media companies (Wulf and Zarnekow 2011). In this context, the contribution of business and information systems engineering can manifest itself in two ways: On the one hand, it is essential to intensively deal with the potential of telecommunication services in the design of modern information systems and to support current developments in this area. Quality of service, content delivery networks, network neutrality or the expansion of broadband networks are just some example topics of research. On the other hand, business and information systems engineering can also exert an influence in the opposite direction because telecommunication providers often lack insight of the concrete requirements and scenarios of the users ("business use case") and what role telecommunication services can play in companies' information systems.

ICT providers pursue independent strategies, have specific (business) processes and use special information systems. Thus, all three aspects provide research questions that are interesting to business and information systems engineering. The consideration of the ICT providers' sourcing, production and distribution strategies leads to questions concerning the development of innovative business models, the development of ICT product and market strategies, the design of ICT product catalogues, the analysis of the value chain, industry and market structures or the determination of the intensity of production. At the process level, a consistent analysis of provider-specific process models ought to be made, which often differ from traditional models in business and information systems engineering. While users typically use frameworks such as ITIL or COBIT (both are established areas of research in the field of business and information systems engineering as well) as the basis for the design of their internal ICT processes, telecommunication providers mostly use other standards, particularly eTOM (Salcher and Stieber 2006). There are also differences at the system level. Hence, application system landscapes of telecommunication providers are typically divided into operations support systems (OSS) and business support systems (BSS) and the customization and the interfaces of these systems are subject of intense discussions. It is here, business and information systems engineering can make an important contribution.

Prof. Dr. Rüdiger Zarnekow Dr. Koray Erek Technische Universität Berlin Lehrstuhl für Informations- und Kommunikationsmanagement

\section{ICT Providers: A Subject of Business and Information Systems Engineering or Not?}

Technologically driven processes of change and transformation do not only result for company, value chain, market and industry structures that have grown over time, but also for (university) disciplines and their corresponding contents of research and teaching.

(Telecommunications) Convergence is progressing rapidly and previously distinct technical infrastructures, terminal devices and application systems are consolidated in the course of comprehensive social digitization and interconnection; this development also gives rise to new 
solutions to previous challenges or, partially, even to completely new challenges. Examples include the different forms of outsourcing, which are intertwined with the boundaries of an enterprise - new possibilities of designing, controlling and using of integrated business processes (on part of providers and users!), which result from changing value chain architectures, or innovative business models, which - apart from emerging markets can and have to use changed strategic design options (e.g., in terms of using internally and externally available data, shifts in the limits of markets/ranges of service due to product service systems as well as digitized/interconnected creation and usage processes or the combination of various coordination mechanisms and sources of revenue).

The consolidation of traditional subjects of business and information systems engineering with other subjects (including ICT), which results from (telecommunications) convergence, is therefore not another attempt to discredit, to take up trendy topics, or expand the field of business and information systems engineering beyond proven fields of competence while finding new catchphrases at the same time; it is rather a necessary process of development in order to adequately face current challenges of science and daily business. The familiar "world of computers" is not only becoming increasingly closer to telecommunications but also with traditionally more distinct areas, e.g., medical technology used in health care, facilities and automotive engineering and/or energy supply.

If business and information systems engineering is willing and expected to contribute to the reflection of the implications of central, social challenges (e.g., energy transition or demographic change), or to the so-called "high-tech strategy" of the German government, or to the current discussion of the enquiry commission "internet and digital society" of the German parliament, it has to complement traditional subjects of other disciplines and to extend them by new issues.
Business and information systems engineering does not only have to follow the developments of daily business, i.e., so that, apart from traditional hardware, software and IT service providers, the so-called ICT providers significantly affect the society's digitization and interconnection as well; it also has to anticipate the process of convergence and choose and complete its perspective beyond these groups that are involved.

Having said that, the request to contribute to this article was surprising, as immediately the question emerged: What would be the reverse consequence? ICT providers are NOT a theme of business and information systems engineering. Business and information systems engineering would not only lose its status as a contributor of findings and explanations to current and future challenges; it would also impede that previous results relating to central issues to the further development of a digitized and interconnected society would have no attention. This includes, e.g., the following established subjects of business and information systems engineering: issues related to open and integrated infrastructures, (information) systems and (software and service) architectures, process integration (on part of providers and users) or data protection and data security. In addition to these established subjects, business and information systems engineering has also got to address the scientific analysis and accomplishment of new challenges. This includes, e.g., the interoperability in interconnected areas of life (mobility, energy, health care, education, etc.), technical, economic and social implications of the power of, e.g., collaborative filtering which is increasingly used as a more efficient tool of analysis for enormous data sets (which are build and used by individuals), as well as the reflection and development of changed or completely new business models. The corresponding models relating to markets, ranges of services, production and sources of revenue of established and, future software and $\mathrm{I}(\mathrm{C}) \mathrm{T}$ providers are not only subject to fundamental processes of transformation; they will also affect other industries' significant, digitized and interconnected framework conditions for economic activities.

This development of convergence is surely associated with certain "fears" and reservations, since more and more interdisciplinary communication and cooperation are required. But if we avoid trying only to find new catchphrases and are able to succeed in developing the necessary and inevitable perspective on business and information systems engineering so that it can contribute to significant scientific and social issues, then the above question virtually answers itself: ICT providers must be an essential subject of business and information systems engineering!

Prof. Dr. Martin Gersch FU Berlin

Department Wirtschaftsinformatik

\section{References}

\section{To: Section 3}

Zoltners A (2006). Kellogg School of Management

\section{To: Section 5}

Buxmann P, Diefenbach H, Hess T (2011) Die Softwareindustrie - Ökonomische Prinzipien, Strategien, Perspektiven, 2nd edn. Springer, Heidelberg

Cusumano M (2004) The business of software. Simon \& Schuster, New York

\section{To: Section 6}

Salcher S, Stieber R (2006) Process Support System - Architektur als Erfolgsfaktor für Kommunikationsanbieter im IKTZeitalter. Elektrotechnik \& Informationstechnik (123):333-343

Wulf J, Zarnekow R (2011) Cross-sector competition in telecommunications. An empirical analysis of diversification activities. Business \& Information Systems Engineering 3(5):289-298 